\title{
Article \\ MR Imaging-Pathologic Correlation of Uveal Melanomas Undergoing Secondary Enucleation after Proton Beam Radiotherapy
}

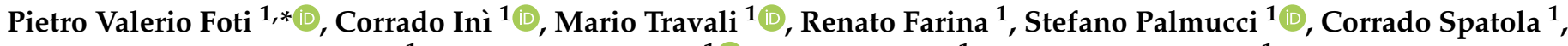 \\ Rocco Luca Emanuele Liardo ${ }^{1}$, Roberto Milazzotto ${ }^{1}{ }^{10}$, Luigi Raffaele ${ }^{1}$, Vincenzo Salamone ${ }^{1}$, \\ Rosario Caltabiano $^{2}$ (D), Giuseppe Broggi ${ }^{2}$ (D) Lidia Puzzo $^{2}$, Andrea Russo ${ }^{3}$ (D) Michele Reibaldi ${ }^{3}$ (D), \\ Antonio Longo ${ }^{3}$, Paolo Vigneri ${ }^{4}$, Massimo Venturini ${ }^{5}$ and Antonio Basile ${ }^{1}$
}

check for updates

Citation: Foti, P.V.; Inì, C.; Travali, M.; Farina, R.; Palmucci, S.; Spatola, C.; Liardo, R.L.E.; Milazzotto, R.; Raffaele, L.; Salamone, V.; et al. MR Imaging-Pathologic Correlation of Uveal Melanomas Undergoing Secondary Enucleation after Proton Beam Radiotherapy. Appl. Sci. 2021 11, 4310. https://doi.org/ 10.3390/app11094310

Academic Editor: Qi-Huang Zheng

Received: 27 February 2021

Accepted: 4 May 2021

Published: 10 May 2021

Publisher's Note: MDPI stays neutral with regard to jurisdictional claims in published maps and institutional affiliations.

Copyright: (c) 2021 by the authors. Licensee MDPI, Basel, Switzerland. This article is an open access article distributed under the terms and conditions of the Creative Commons Attribution (CC BY) license (https:// creativecommons.org/licenses/by/ $4.0 /)$.
1 Radiology I Unit, Department of Medical Surgical Sciences and Advanced Technologies “G.F. Ingrassia”, University Hospital Policlinico "G. Rodolico-San Marco", Via Santa Sofia 78, 95123 Catania, Italy; corrado.ini@gmail.com (C.I.); mario.travali.a34l@gmail.com (M.T.); radfaro@hotmail.com (R.F.); spalmucci@sirm.org (S.P.); cor_spatola@hotmail.com (C.S.); Lucaliardo@hotmail.com (R.L.E.L.); Robertomilazz@hotmail.it (R.M.); raffaele@lns.infn.it (L.R.); vincenzosalamone@hotmail.com (V.S.); basile.antonello73@gmail.com (A.B.)

2 Section of Anatomic Pathology, Department of Medical Surgical Sciences and Advanced Technologies “G.F. Ingrassia", University of Catania, Via Santa Sofia 78, 95123 Catania, Italy; rosario.caltabiano@unict.it (R.C.); giuseppe.broggi@gmail.com (G.B.); lipuzzo@unict.it (L.P.)

3 Department of Ophthalmology, University of Catania, Via Santa Sofia 78, 95123 Catania, Italy; andrearusso2000@hotmail.com (A.R.); mreibaldi@libero.it (M.R.); antlongo@unict.it (A.L.)

4 Center of Experimental Oncology and Hematology, Department of Clinical and Experimental Medicine, University Hospital Policlinico "G. Rodolico-San Marco", Via Santa Sofia 78, 95123 Catania, Italy; vigneripaolo@gmail.com

5 Diagnostic and Interventional Radiology Department, Circolo Hospital, Insubria University, 21100 Varese, Italy; massimo.venturini@uninsubria.it

* Correspondence: pietrofoti@hotmail.com; Tel.: +39-09-5378-2360

Abstract: Background: Currently, radiotherapy represents the most widely employed therapeutic option in patients with uveal melanoma. Although the effects of proton beam radiotherapy on uveal melanoma end ocular tissues have been histologically documented, their appearance at MR imaging is still poorly understood. The purpose of our study was to elucidate the magnetic resonance (MR) semiotics of radiotherapy-induced changes to neoplastic tissues and ocular structures in patients with uveal melanoma undergoing secondary enucleation after proton beam radiotherapy. Methods: Nine patients with uveal melanoma who had undergone proton beam radiotherapy, MR imaging, and subsequent secondary enucleation were retrospectively selected. The histopathologic findings evaluated for irradiated tumors were necrosis, fibrosis, and viable tumor, while the histopathologic findings evaluated for extratumoral ocular/periocular tissues were radiation-related intraocular inflammation, vitreous hemorrhage, optic nerve degeneration, iris neovascularization, and periocular fibrotic adhesions. On MR images, the appearance of the abovementioned histologic features was assessed on conventional and diffusion-weighted sequences. Results: T2-weighted sequences performed better in detecting radiation-induced necrosis, fibrosis, optic nerve degeneration, and periocular fibrotic adhesions. T1-weighted sequences were preferable for identifying cataracts, vitreous hemorrhage, and inflammatory complications. Contrast-enhanced T1-weighted sequences were irreplaceable in assessing iris neovascularization, and in confirming inflammatory complications. Conclusions: In the light of their increasing role in the multidisciplinary management of patients with uveal melanoma, radiologists should be aware of the MR appearance of the effects of radiotherapy on neoplastic and ocular tissue, in order to improve the accuracy of follow-up MR examinations.

Keywords: magnetic resonance imaging (E01.370.350.825.500); diffusion magnetic resonance imaging (E01.370.350.825.500.150); melanoma (C04.557.465.625.650.510); eye (E01.370.350.825.500.150); proton therapy (E02.815.250.500); brachytherapy (E02.815.150); necrosis (C23.550.717) 


\section{Introduction}

Uveal melanoma accounts for about $3 \%$ of all melanomas. Even though uveal melanoma is rather uncommon (incidence of 5.1 cases per million person-years), it represents the most frequent primary intraocular malignancy in the adult population [1,2]. The neoplasm originates from uveal melanocytes, in descending order of frequency, from the choroid $(90 \%)$, the ciliary body $(6 \%)$, or the iris (4\%) [2-4].

Today, three different histologic types of uveal melanoma are recognized: spindle cell, epithelioid cell, and mixed cell type [5-7]. Various prognostic factors may influence the patient's outcome. In particular, ciliary body involvement, extraocular extension, diffuse growth pattern, some histopathological features (epithelioid cell type), and genetic factors (monosomy 3, 6p gain, or loss of BAP-1 gene) are associated with a more severe prognosis and increased risk of metastases [5].

The diagnosis is essentially entrusted to clinical evaluation and ophthalmological imaging methods; nevertheless, currently, radiological imaging techniques play a critical role in the clinical management of patients with uveal melanoma. In particular, magnetic resonance imaging (MRI) has multifaceted utility for a variety of different purposes: confirmation of clinical diagnosis, assessment of disease extent, evaluation and prediction of tumor response to radiotherapy treatment, follow-up, and detection of local radiotherapyrelated complications [8-11].

Enucleation and, more recently, radiotherapy (plaque brachytherapy and proton beam radiotherapy) represent the two pillars underpinning the local treatment of uveal melanoma. Since the initial observations of Zimmerman et al. [12], different studies and trials have proven no significant difference in terms of mortality between eye-sparing radiation therapies and surgery [13-17]; therefore, over the last few decades, radiotherapy techniques have gained in importance, and currently represent the most widely used therapeutic option [1].

Enucleation is currently reserved for a few indications: large tumors (basal diameter $>20 \mathrm{~mm}$, thickness $>12 \mathrm{~mm}$ ), and uveal melanomas with optic nerve or orbital involvement. Enucleation can be divided into the following types: (1) primary, in patients who do not undergo any other type of therapy, and (2) secondary, in patients already treated with eye-conserving radiotherapy. Indications for secondary enucleation include tumor progression after radiotherapy (local recurrence or extrascleral extension) and treatment-related complications (e.g., ocular pain, vision loss, vitreous hemorrhage, neovascular glaucoma, or chronic inflammation) [18-20]. Over the years, considerable progress has been made in radiotherapy techniques and in the management of radiation-related complications; hence, both primary and secondary enucleation have become less frequent. In different series the rate of secondary enucleation after radiotherapy is up to $12.5 \%[17,21]$.

Although proton beam radiotherapy has been used in the treatment of uveal melanomas since 1975 [22], only a few authors have reported histopathologic findings of irradiated eyes undergoing secondary enucleation; owing to the rarity of neoplasm and of enucleation, the latter becoming increasingly rare, the scientific literature dealing with this topic is scant. The first articles dealing with the histopathologic and ultrastructural features of uveal melanomas enucleated after prior proton beam radiotherapy date back to the 1980s [22-25]. In these studies, patients underwent enucleation because of treatment failure $[23,25]$ or clinical treatment-related complications [22,24,25]. A- and B-scan ultrasonographies (US) were used as imaging methods to study uveal melanomas before enucleation [22-24]; nevertheless, a real radiologic-pathologic correlation was not performed. Lemke et al. [26] were the first to carry out a correlation between MR and histologic findings in enucleated eyes with uveal melanoma; however, patients underwent primary enucleation and, therefore, did not incur any kind of radiotherapy.

The histologic appearance of eyes with uveal melanoma undergoing primary enucleation is very different from that of eyes undergoing secondary enucleation; this is due to radiation-related changes observable in the latter $[19,27]$. 
At present, the effects of proton beam radiotherapy on both melanoma cells and healthy ocular/periocular structures have been well documented from a histological point of view [22-25,27-29]; nevertheless, much less is known about their appearance under MR imaging.

In our study we focused on the MR imaging-pathologic correlation of uveal melanomas undergoing secondary enucleation after proton beam radiotherapy. In particular, our aim was to elucidate the MR semeiotics of radiotherapy-induced changes on both neoplastic tissues and healthy ocular structures.

\section{Materials and Methods}

\subsection{Patients}

Our single-institution retrospective cohort study was carried out in accordance with the Code of Ethics of the World Medical Association (Declaration of Helsinki) for experiments involving humans, and in accordance with the recommendations of our local ethics committee. Informed consent was waived because of the retrospective design of the study.

Employing the search software of our picture archiving and communication system (PACS) and the Anatomic Pathology Section database, we identified patients affected by uveal melanoma who had undergone MR examination and subsequent enucleation between September 2016 and December 2020. Among these patients, those who underwent secondary enucleation were considered for eligibility in our study. Patient inclusion criteria were as follows: proton beam radiotherapy performed as primary treatment for uveal melanoma at INFN LNS Nuclear Physics Laboratory, Catania (Istituto Nazionale di Fisica Nucleare INFN_Laboratori Nazionali del Sud, Catania); MR examination (brain and orbit) performed at our department before enucleation; secondary enucleation performed within 2 weeks of MR examination; histopathologic diagnosis of uveal melanoma. Patient exclusion criteria were as follows: incomplete MR protocol; poor quality of MR images; interval between MR examination and enucleation greater than 2 weeks; incomplete radiotherapeutic treatment; radiotherapy treatment other than proton beam radiotherapy. Demographic information and the reason for enucleation were recorded.

\subsection{Proton Beam Therapy Protocol}

All patients underwent proton beam radiotherapy at the INFN LNS Nuclear Physics Laboratory (Istituto Nazionale di Fisica Nucleare INFN_Laboratori Nazionali del Sud, Catania), using a superconducting cyclotron that delivers a $62-\mathrm{MeV}$ proton beam [30]. A total dose of $60 \mathrm{GyRBE}$ (Gray relative biological effectiveness, taking into account a constant RBE of 1.1 over the modulated Bragg peak) was split into four consecutive daily fractions of 15 GyRBE. EYEPLAN, a dedicated software developed at Massachusetts General Hospital by Goitein and Miller [31], was used for treatment planning.

\subsection{MR Protocol}

All MR examinations were performed using a closed-configuration superconducting 1.5-T MRI unit (Signa HDxT; GE Healthcare, Milwaukee, WI, USA) with $57.2 \mathrm{mT} / \mathrm{m}$ gradient strength and $120 \mathrm{~T} / \mathrm{m} / \mathrm{s}$ slew rate, by means of an 8-channel high-resolution neurovascular phased-array coil with array spatial sensitivity technique (ASSET) parallel acquisition. All patients underwent an MR examination of the brain and orbit. MR pulse sequences and corresponding imaging parameters of our MR protocol of the orbit are summarized in Table 1. 
Table 1. Orbital MRI protocol. The synoptic table summarizes the imaging parameters of the MR sequences. T1-weighted FSE spectral presaturation sequences were performed before and after the intravenous administration of $0.2 \mathrm{~mL}$ gadoteric acid (gadoterate dimeglumine, Dotarem, $0.5 \mathrm{~mol} / \mathrm{L}$; Guerbet, Roissy, Charles-de-Gaulle Cedex; France) per kilogram of body weight. DW imaging sequence was performed before contrast medium administration. All sequences had a field of view that included orbital structures, lids, and the optic chiasm.

\begin{tabular}{|c|c|c|c|c|c|}
\hline MRI Protocol & T2W FSE & T2W FSE STIR & T1W FSE & T1W FSE Fat Sat & DWI SE EPI \\
\hline Acquisition plane & axial, coronal & axial, coronal & axial, coronal & axial, coronal & axial \\
\hline $\begin{array}{c}\text { Repetition time/Echo } \\
\text { time (msec) }\end{array}$ & $3220 / 120$ & $3700 / 50$ & $550 / 14.9$ & $450 / 15.1$ & $4800 / 89.9$ \\
\hline Flip angle & $90^{\circ}$ & $90^{\circ}$ & $90^{\circ}$ & $90^{\circ}$ & $90^{\circ}$ \\
\hline Echo train length & 19 & 12 & 2 & 2 & - \\
\hline N. of averages & 4 & 3 & 3 & 2 & 8 \\
\hline Section thickness (mm) & 3 & 3 & 3 & 3 & 4 \\
\hline Interslice gap (mm) & 0.3 & 0.3 & 0.3 & 0.3 & 0.4 \\
\hline Field of view (mm) & $160 \times 160$ & $160 \times 160$ & $160 \times 160$ & $160 \times 160$ & $200 \times 200$ \\
\hline Matrix & $352 \times 256$ & $256 \times 256$ & $256 \times 224$ & $256 \times 256$ & $192 \times 192$ \\
\hline Frequency direction & Superior to inferior & $\begin{array}{l}\text { Anterior to } \\
\text { posterior }\end{array}$ & Right to left & Right to left & Right to left \\
\hline b-value $\left(\mathrm{sec} / \mathrm{mm}^{2}\right)$ & - & - & - & - & $0-1000$ \\
\hline
\end{tabular}

$\mathrm{T} 1 \mathrm{~W}=\mathrm{T} 1$-weighted; T2W = T2-weighted; FSE = fast spin-echo; STIR = short tau inversion recovery; fat sat = fat saturation; DWI = diffusion-weighted imaging; $\mathrm{SE}=$ spin-echo; $\mathrm{EPI}$ = echo-planar imaging.

\subsection{Histopathology}

Enucleated specimens were fixed in formaldehyde, paraffin processed, cut, and stained with hematoxylin-eosin following the routine protocol. Specifically, specimens were cut at $90^{\circ}$ to the plane of the lesion, including the median portion of the eye, encompassing the tumor, cornea, and optic disk. Histological slides were available for diagnostic review in all cases. On enucleated eyes two pathologists jointly recorded and evaluated determined histopathologic features on both irradiated tumors and extratumoral ocular tissues. On irradiated tumors the following histopathologic findings were evaluated: necrosis, fibrosis, and viable tumor tissue. On irradiated extratumoral ocular/periocular tissues the following histopathologic findings were evaluated: radiation-related intraocular inflammation (uveitis, endophthalmitis, and chronic conjunctivitis), vitreous hemorrhage, optic nerve degeneration, iris neovascularization, and periocular fibrotic adhesions.

\subsection{Image Analysis}

MR images were matched with corresponding histological sections (histopathology slides), taking into account specific anatomic landmarks such as the optic disc and ciliary body. On MR images the appearance of the abovementioned histologic features was recorded and assessed on both conventional sequences (T1-weighted and T2-weighted) and diffusion-weighted imaging (DWI) sequences, by two radiologists. According to the purposes of the study, the radiologists were not blinded to the clinical history of the patients. Moreover, on the MR images, the radiologists evaluated the appearance of the lens and, in particular, the radiation-related cataract. These findings were not assessed in terms of histopathology; therefore, they were correlated with the most recent preoperative clinical examination.

\section{Results}

\subsection{Patients}

On the basis of the abovementioned criteria, 11 patients were identified for potential inclusion in the study. Of these patients, two had to be excluded: one because of inadequate quality of MR images, the other because of plaque brachytherapy treatment. Therefore, the final enrolled population included nine patients (six men, three women). The patients mean age at irradiation was 55.5 years (range $29-78$ years). The time interval between irradiation and enucleation ranged from 12 months to 46 months. The reasons for secondary 
enucleation were as follows: tumor progression after radiation therapy (local recurrence or extrascleral extension) $(n=4)$, treatment-related complications (ocular pain, vision loss, vitreous hemorrhage, neovascular glaucoma, or chronic inflammation) $(n=2)$ or both $(n=3)$. The demographic data of our case series are summarized in Table 2.

Table 2. Demographic data of the enrolled population.

\begin{tabular}{|c|c|c|c|c|c|c|}
\hline Patient & Gender & Age & Eye & Tumor Location & $\begin{array}{c}\text { Interval between Irradiation } \\
\text { and Enucleation }\end{array}$ & Reasons for Enucleation \\
\hline 1 & Male & 65 & Left & Choroid & 36 months & $\begin{array}{c}\text { Tumor } \\
\text { progression/recurrence } \\
\text { and treatment-related } \\
\text { complications }\end{array}$ \\
\hline 2 & Female & 72 & Left & Choroid & 46 months & $\begin{array}{l}\text { Treatment-related } \\
\text { complications }\end{array}$ \\
\hline 3 & Male & 60 & Right & Choroid & 35 months & $\begin{array}{c}\text { Tumor } \\
\text { progression/recurrence }\end{array}$ \\
\hline 4 & Male & 29 & Right & Choroid & 34 months & $\begin{array}{c}\text { Tumor } \\
\text { progression/recurrence } \\
\text { Tumor }\end{array}$ \\
\hline 5 & Male & 37 & Right & Choroid & 38 months & $\begin{array}{l}\text { progression/recurrence } \\
\text { and treatment-related } \\
\text { complications }\end{array}$ \\
\hline 6 & Male & 58 & Right & Choroid & 12 months & $\begin{array}{c}\text { Treatment-related } \\
\text { complications }\end{array}$ \\
\hline 7 & Male & 44 & Right & Choroid & 32 months & $\begin{array}{c}\text { Tumor } \\
\text { progression/recurrence } \\
\text { Tumor }\end{array}$ \\
\hline 8 & Female & 75 & Left & Choroid & 14 months & $\begin{array}{l}\text { progression/recurrence } \\
\text { and treatment-related } \\
\text { complications }\end{array}$ \\
\hline 9 & Female & 78 & Right & Choroid & 18 months & $\begin{array}{c}\text { Tumor } \\
\text { progression/recurrence }\end{array}$ \\
\hline
\end{tabular}

\subsection{Histopathologic Findings}

3.2.1. Histopathologic Findings with Respect to Irradiated Tumors

Radiation-induced necrosis was found in $5 / 9$ patients. It was characterized by intratumoral coagulation and liquefaction necrosis, with dispersion of melanin pigment and enrichment with melanophages.

Fibrosis occurred in 1/9 patients, and was characterized by scar-like collagen bundles that replaced previously viable tumor tissue.

Viable tumor tissue was found in $7 / 9$ patients. It was characterized by the presence of visible neoplastic cells with a distinct nucleus.

The histopathologic features of the enucleated specimens are summarized in Table 3.

Table 3. Histopathologic and MRI findings with respect to irradiated and subsequently enucleated tumors.

\begin{tabular}{|c|c|c|c|c|c|c|c|}
\hline \multirow{2}{*}{$\begin{array}{c}\text { Patient } \\
1\end{array}$} & \multirow{2}{*}{$\begin{array}{l}\text { Histologic Type } \\
\text { Epithelioid cell }\end{array}$} & \multicolumn{2}{|c|}{$\begin{array}{c}\text { Radiation-Induced } \\
\text { Necrosis Histology MRI }\end{array}$} & \multicolumn{2}{|c|}{ Fibrosis Histology MRI } & \multicolumn{2}{|c|}{$\begin{array}{c}\text { Viable Tumor Tissue } \\
\text { Histology MRI }\end{array}$} \\
\hline & & - & - & - & - & Yes & Yes \\
\hline 2 & $\begin{array}{l}\text { Necrosis without viable } \\
\text { tumor tissue }\end{array}$ & Yes & Yes & - & - & - & - \\
\hline 3 & Spindle cell & Yes & Yes & - & - & Yes & Yes \\
\hline 4 & Epithelioid cell & Yes & Yes & - & - & Yes & Yes \\
\hline 5 & Spindle cell & - & - & - & - & Yes & Yes \\
\hline 6 & $\begin{array}{l}\text { Fibrotic scar without viable } \\
\text { tumor tissue }\end{array}$ & - & - & Yes & Yes & - & - \\
\hline 7 & Spindle cell & Yes & Yes & - & - & Yes & Yes \\
\hline 8 & Mixed cell type & - & - & - & - & Yes & Yes \\
\hline 9 & Mixed cell type & Yes & - & - & - & Yes & Yes \\
\hline
\end{tabular}




\subsubsection{Extratumoral Histopathologic Findings}

The histologic appearance of irradiated extratumoral ocular tissues was as follows:

- Radiation-related intraocular inflammation (uveitis, endophthalmitis, and chronic conjunctivitis) (3/9 patients): presence of a conspicuous inflammatory infiltratemainly composed of lymphocytes, plasma cells, and granulocytes-populating the extratumoral ocular tissues.

- Vitreous hemorrhage (2/9 patients): extravasation of red blood cells within and around the vitreous body.

- Optic nerve degeneration (3/9 patients): gliosis and loss of axonal tissue, which was replaced by fibrosis.

- Iris neovascularization (1/9 patients): enrichment of blood vessels on the iris' surface.

- Periocular fibrotic adhesions (1/9 patients): bands of scar-like tissue.

Extratumoral histopathologic findings are summarized in Table 4.

Table 4. Histopathologic findings with respect to irradiated extratumoral ocular tissues.

\begin{tabular}{cccccc}
\hline Patient & $\begin{array}{c}\text { Radiation-Related } \\
\text { Intraocular Inflammation }\end{array}$ & $\begin{array}{c}\text { Vitreous } \\
\text { Hemorrhage }\end{array}$ & $\begin{array}{c}\text { Optic Nerve } \\
\text { Degeneration }\end{array}$ & $\begin{array}{c}\text { Iris Neovascular- } \\
\text { ization }\end{array}$ & $\begin{array}{c}\text { Periocular } \\
\text { Fibrotic Adhesion }\end{array}$ \\
\hline 1 & - & Yes & - & - & - \\
2 & Yes & - & - & - & - \\
3 & - & - & - & - & - \\
4 & - & - & Yes & - & - \\
5 & Yes & - & - & - & - \\
6 & Yes & - & - & - & - \\
7 & - & Yes & - & - & - \\
\hline
\end{tabular}

\subsection{MR Findings}

\subsubsection{MR Findings with Respect to Irradiated Tumors}

The MR findings with respect to irradiated tumors are summarized in Table 3.

After MR imaging, radiation induced necrosis was appreciable in 4/9 patients. Radiationinduced necrosis showed high signal intensity on T1-weighted, low signal intensity on T2-weighted, no restriction on DW images, and no enhancement on contrast-enhanced fatsuppressed T1-weighted images (Figure 1). In the one remaining patient with histopathologic evidence of necrosis (Table 3), the irradiated tumor was characterized by microscopic foci of necrosis, only appreciable under pathologic examination and, therefore, below the resolving power (spatial resolution) of MR imaging.

At MR imaging fibrosis was appreciable in $1 / 9$ patients. Fibrosis showed intermediate signal intensity on T1-weighted images, low signal intensity on T2-weighted images, no restriction on DW images, and moderate enhancement on contrast-enhanced fat-suppressed T1-weighted images.

At MR imaging viable tumor tissue was appreciable in $7 / 9$ patients. The MR appearance of viable tumor tissue resembled that of primary melanoma, largely depending on the melanin content. Typical pigmented melanomas showed high signal intensity on T1weighted images and low signal intensity on T2-weighted images. Poorly pigmented lesions demonstrated intermediate signal intensity on both T1- and T2-weighted sequences. In any case, viable tumor tissue displayed restricted diffusion on DW sequences (high signal intensity on DW images, low signal intensity on the ADC map) due to high cellularity. Table 5 summarizes the MR imaging appearance of irradiated uveal melanomas. 

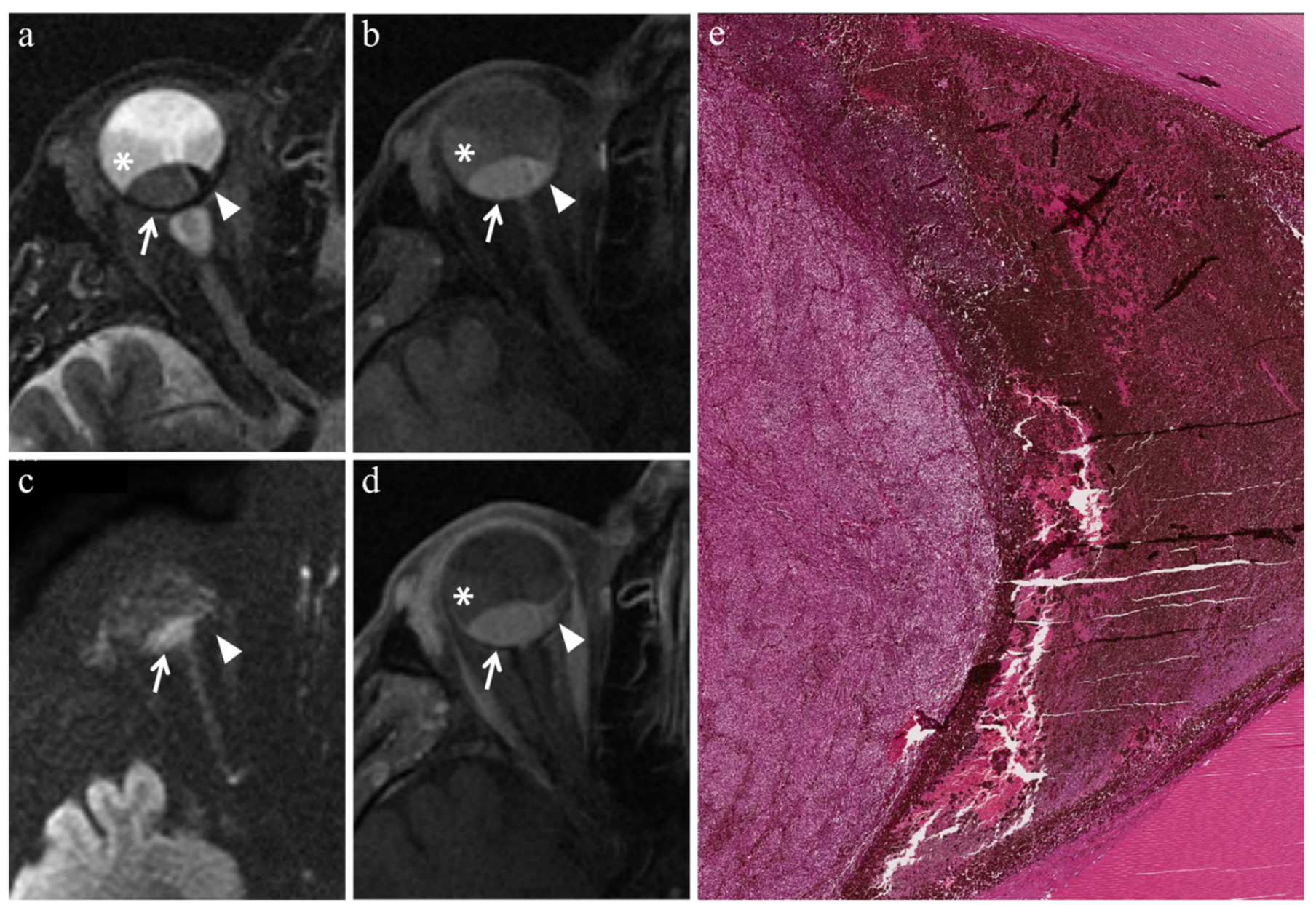

Figure 1. Radiation-induced necrosis. A 60-year-old male patient (patient $\mathrm{n}$. 3 of our series) affected by choroidal melanoma of the right eye treated with proton beam radiotherapy. Secondary enucleation was performed 35 months after radiotherapy because of local recurrence. Axial (a) T2-weighted turbo spin-echo STIR, (b) fat-suppressed T1-weighted, (c) DW $\left(\mathrm{b}=1000 \mathrm{~s} / \mathrm{mm}^{2}\right)$, and (d) contrast-enhanced fat-suppressed T1-weighted images. A dome-shaped mass along the posterior aspect of the globe, covering the optic disc, shows central and lateral portions (white arrows) with intermediate signal intensity on the T2-weighted image and moderately high signal intensity on the T1-weighted image, indicative of viable tumor; the medial portion of the lesion (white arrowhead) exhibits low signal intensity on the T2-weighted image and high signal intensity on the T1-weighted image-a finding consistent with radiation-induced necrosis characterized by dispersion of the melanin pigment. The sharp boundary that separates the two different components of the lesion is better visible on the T2-weighted image. The viable tumor (white arrow) shows restricted diffusion with high signal intensity due to high cellularity on the DW image, and mild enhancement on the contrast-enhanced fat-suppressed T1-weighted image; the medial necrotic part (white arrowhead) displays no restriction on DW image and lack of contrast enhancement on T1-weighted image. Note a retinal detachment (white asterisks), lateral to the mass, with intermediate signal intensity on the T2- and T1-weighted images, and without contrast enhancement. (e) Histological examination (H\&E, original magnification $100 \times$ ) shows a sharp transition within the tumor between the vital tissue (on the left) and the necrotic component, with extensive dispersed melanin (on the right). 
Table 5. Chart summarizing the MR imaging appearance of irradiated uveal melanomas.

\begin{tabular}{|c|c|c|c|c|}
\hline MR Finding & $\mathrm{T} 2$ & T1 & Gd-T1 & DWI \\
\hline $\begin{array}{l}\text { Radiation-induced } \\
\text { necrosis }\end{array}$ & Low signal & High signal & No enhancement & Low signal \\
\hline Fibrosis & Low signal & $\begin{array}{l}\text { Intermediate } \\
\text { signal }\end{array}$ & $\begin{array}{c}\text { Moderate } \\
\text { enhancement }\end{array}$ & Low signal \\
\hline $\begin{array}{l}\text { Viable tumor tissue, } \\
\text { pigmented melanoma }\end{array}$ & Low signal & High signal & $\begin{array}{c}\text { Enhancement of } \\
\text { viable tissue }\end{array}$ & High signal \\
\hline $\begin{array}{c}\text { Viable tumor tissue, } \\
\text { poorly pigmented } \\
\text { melanoma }\end{array}$ & $\begin{array}{c}\text { Intermediate } \\
\text { signal }\end{array}$ & $\begin{array}{l}\text { Intermediate } \\
\text { signal }\end{array}$ & $\begin{array}{c}\text { Enhancement of } \\
\text { viable tissue }\end{array}$ & High signal \\
\hline
\end{tabular}

\subsubsection{Extratumoral MR Findings}

The MR appearance of irradiated extratumoral ocular tissues was as follows:

Radiation-related intraocular inflammation (uveitis, endophthalmitis, and chronic conjunctivitis).

In the case of panuveitis (1/9 patients), MRI showed diffuse thickening of the globe wall that displayed noticeable enhancement on contrast-enhanced fat-suppressed T1-weighted images. This sequence also showed a coexisting diffuse choroidal detachment.

In endophthalmitis (3/9 patients), the anterior chamber and vitreous body showed increased signal intensity on precontrast T1-weighted images. Another typical finding was the high signal intensity of the vitreous body on T2-weighted fluid-attenuated inversion recovery (FLAIR) sequences performed for the brain examination executed concomitantly with the MR of the orbit (Figure 2).

Chronic conjunctivitis (1/9 patients). The conjunctiva appeared thickened with considerable enhancement on contrast-enhanced fat-suppressed T1-weighted sequences.

Vitreous hemorrhage (2/9 patients) was better visible on T1-weighted sequences in which both the anterior chamber and the vitreous body displayed high signal intensity. In 1/2 patients, on T2-weighted images, an intraocular fluid-fluid level, with relative hypointensity of the dependent portion, was identifiable within the vitreous body. On DW images vitreous hemorrhage showed restricted diffusion (Figure 3). 

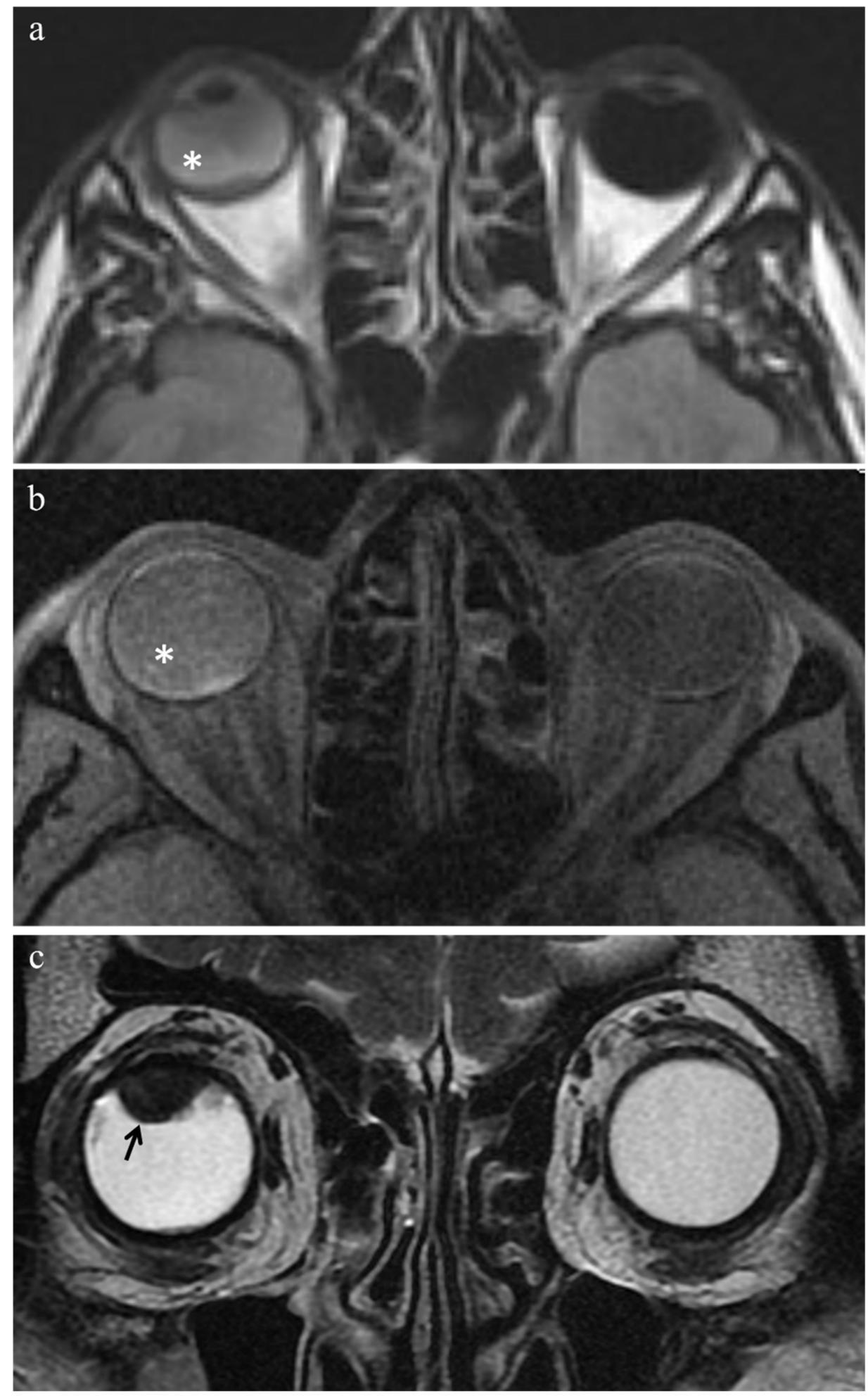

Figure 2. Endophthalmitis. A 37-year-old male patient (patient n. 5 of our series) affected by choroidal melanoma of the right eye treated with proton beam radiotherapy. Secondary enucleation was carried out 38 months after radiotherapy because of local recurrence associated with inflammatory complications and eye pain. Axial (a) T2-weighted FLAIR (from brain MRI scan) and (b) fat-suppressed T1-weighted images show increased signal intensity of the vitreous body of the right eye (white asterisks); this finding is consistent with vitreous inflammation with protein leakage. The contralateral eye shows the physiological water-like hypointense signal. (c) A coronal T2-weighted turbo spin-echo image displays a dome-shaped intraocular choroidal melanoma (black arrow), located along the superior aspect of the right globe, protruding into the posterior chamber. 

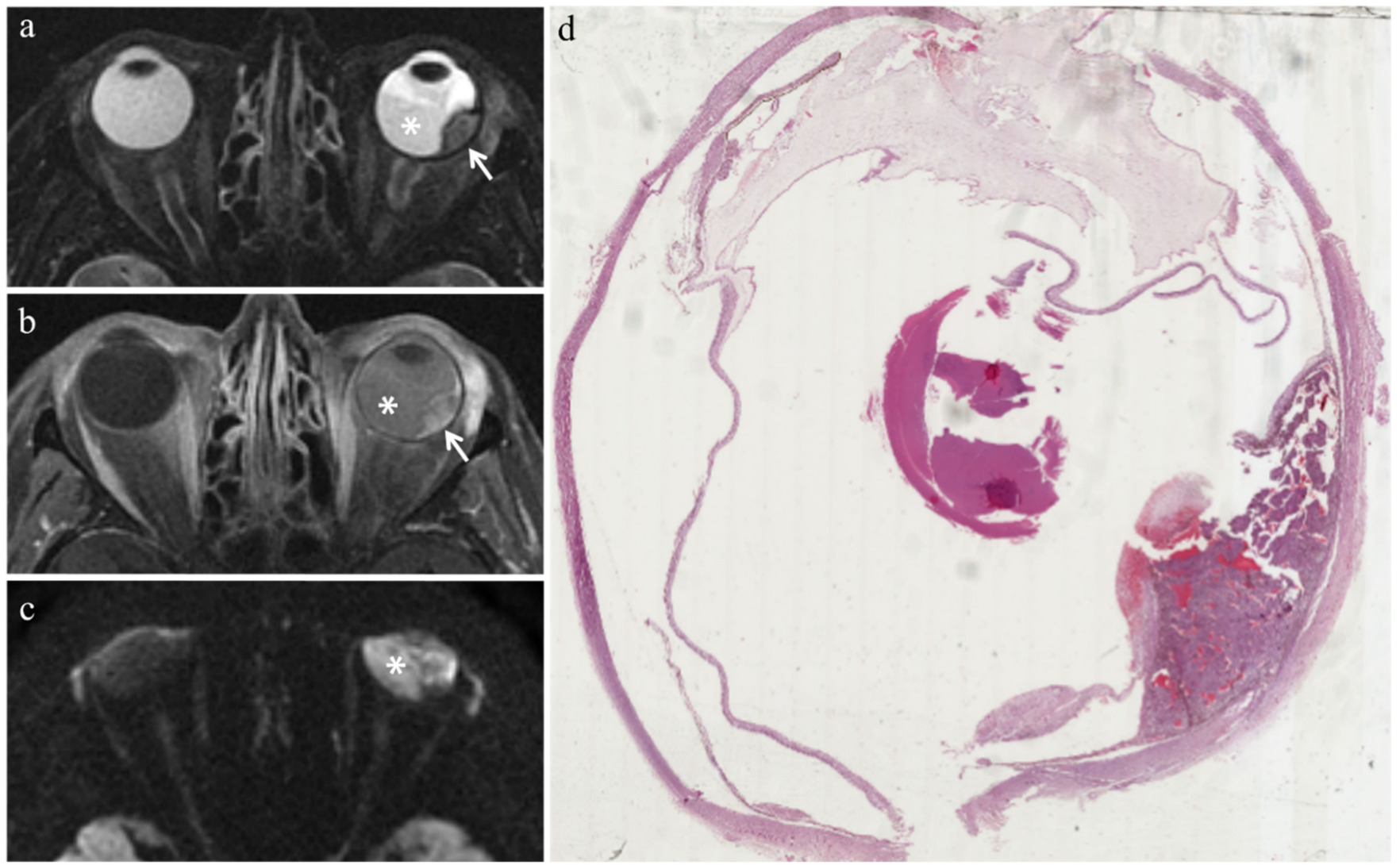

Figure 3. Vitreous hemorrhage. A 75-year-old female patient (patient $\mathrm{n} .8$ of our series) affected by choroidal melanoma of the left eye treated with proton beam radiotherapy. Secondary enucleation was carried out 14 months after radiotherapy because of local recurrence associated with treatment-related complications and eye pain. Axial (a) T2-weighted turbo spin-echo, (b) contrast-enhanced fat-suppressed T1-weighted, and (c) DW (b=1000 s/ $\left.\mathrm{mm}^{2}\right)$ images. The left globe (white asterisks) exhibits increased signal intensity on the T1-weighted image and inhomogeneous signal intensity with fluid-fluid level on the T2-weighted image. On (c) the DW image the left vitreous body shows restricted diffusion with high signal intensity (white asterisk). These findings indicate a diffuse vitreous hemorrhage of the left eye. The physiological water-like signal intensity of the contralateral eye is preserved. A dome-shaped intraocular mass (white arrows in $\mathbf{a}$ and $\mathbf{b}$ ), representing the local recurrence of choroidal melanoma, is located along the temporal aspect of the left globe. (d) Histological examination on low magnification (H\&E, original magnification $25 \times$ ) confirms MRI findings demonstrating a poorly pigmented mass, protruding into the vitreous body, associated with vitreous hemorrhage.

Optic nerve degeneration (3/9 patients). The optic nerve of the affected eye appeared thinned and moderately hyperintense on T2-weighted images in comparison with the contralateral one (Figure 4). 

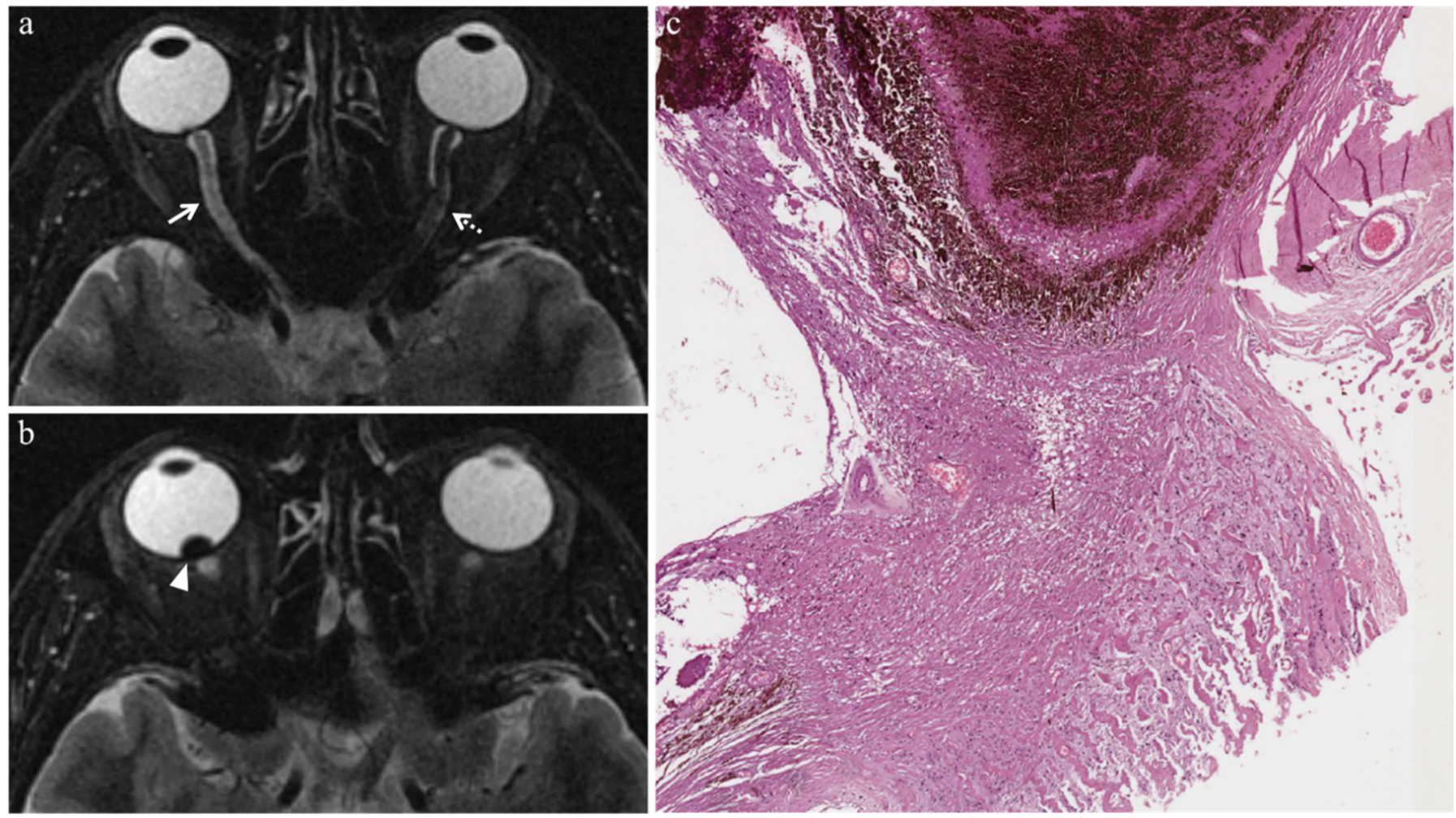

Figure 4. Radiation-induced optic neuropathy. A 44-year-old male patient (patient n. 7 of our series) affected by choroidal melanoma of the right eye treated with proton beam radiotherapy. Secondary enucleation was carried out 32 months after radiotherapy because of tumor progression/local recurrence. (a,b) Axial T2-weighted turbo spin-echo STIR images show a choroidal melanoma (white arrowhead in $b$ ) located along the posterior margin of the globe, partially covering the optic nerve head. The right optic nerve (white arrow in a) is slightly thinner and more hyperintense than the contralateral one (white dotted arrow in a). (c) Histological examination under high magnification (H\&E, original magnification $100 \times$ ) showing the close proximity between the tumor and the optic nerve-which appears slightly compressed, but not infiltrated, with initial signs of degeneration (fibrosis and microcystic changes).

Iris neovascularization (1/9 patients). Conspicuous enhancement of the ciliary body and of the anterior part of the choroid was seen on contrast-enhanced fat-suppressed T1-weighted images.

Radiation induced cataract (1/9 patients). The lens demonstrated a peripheral hyperintense rim on T1-weighted sequences.

Periocular fibrotic adhesions (1/9 patients). Soft tissue thickening, hypointense on T1 and T2-weighted images, was detectable along the outer boundary of the sclera (Figure 5). 

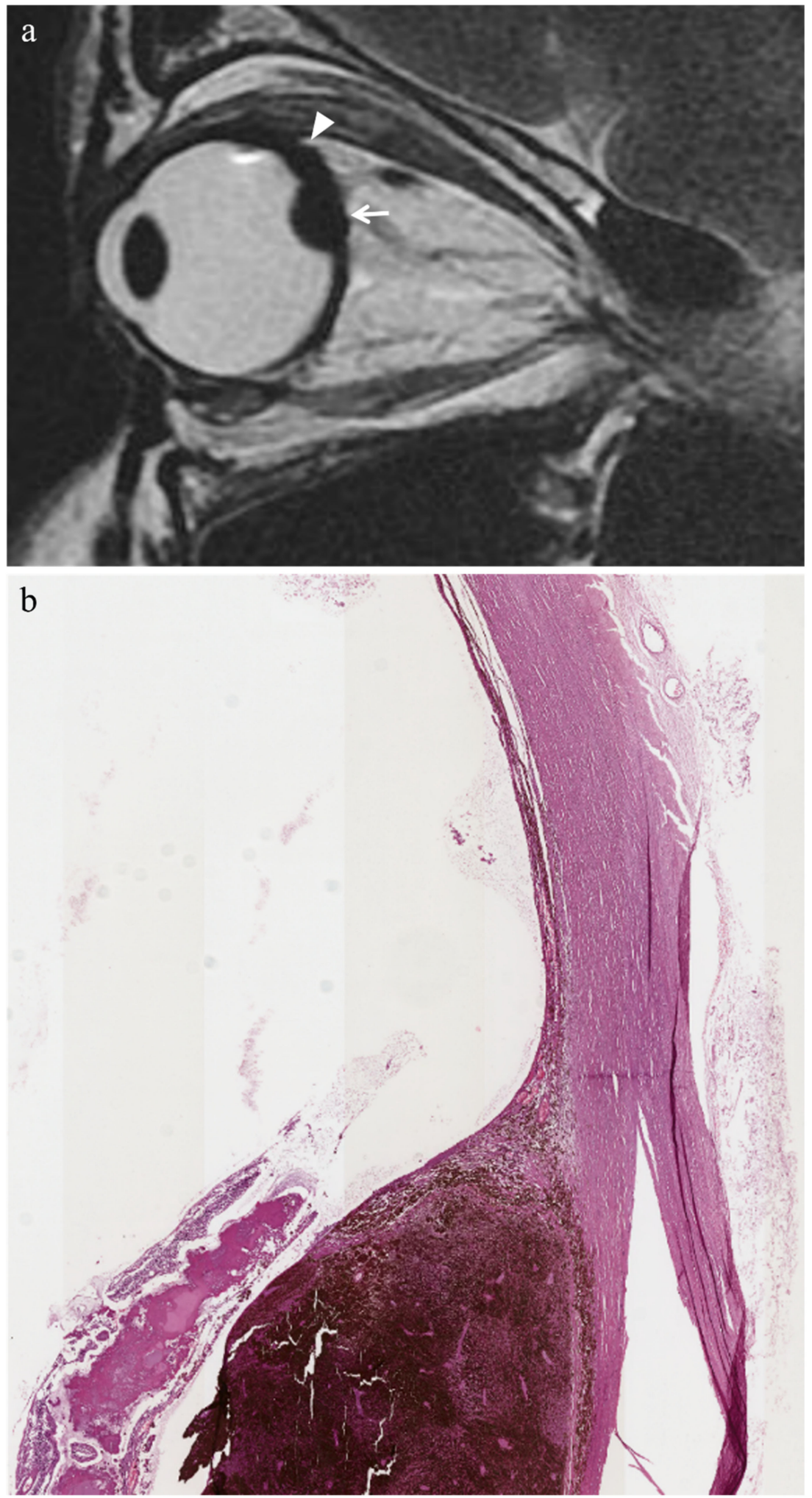

Figure 5. Periocular fibrotic adhesions. A 44-year-old male patient (patient $\mathrm{n} .7$ of our series) affected by choroidal melanoma of the right eye treated with proton beam radiotherapy. The same patient as in Figure 4. (a) Sagittal T2-weighted turbo spin-echo image demonstrates an intraocular choroidal melanoma (white arrow) along the postero-superior aspect of the globe. Hypointense soft tissue thickening (white arrowhead), due to fibrotic adhesions, is seen along the superior outer boundary of the sclera, adjacent to the lesion. (b) Histological detail (H\&E, original magnification $50 \times$ ) shows the moderate thickening and fibrosis of the sclera surrounding the tumor mass. 
Table 6 summarizes the MR imaging appearance of irradiated extratumoral ocular tissues.

Table 6. MR imaging appearance of irradiated extratumoral ocular tissues.

\begin{tabular}{|c|c|c|c|c|}
\hline MR Finding & T2 & T1 & Gd-T1 & DWI \\
\hline Uveitis & High signal & Low signal & Enhancement & $\underbrace{(}_{\text {High signal }}$ \\
\hline Endophthalmitis & $\begin{array}{l}\text { High signal of the } \\
\text { anterior chamber } \\
\text { and vitreous body } \\
\text { on T2-FLAIR }\end{array}$ & $\begin{array}{l}\text { High signal of } \\
\text { the anterior } \\
\text { chamber and } \\
\text { vitreous body }\end{array}$ & - & High signal \\
\hline $\begin{array}{c}\text { Chronic } \\
\text { conjunctivitis }\end{array}$ & & - & Enhancement & \\
\hline $\begin{array}{c}\text { Vitreous } \\
\text { hemorrhage }\end{array}$ & $\begin{array}{c}\text { Variable signal } \\
\text { intensity with } \\
\text { possible fluid-fluid } \\
\text { level }\end{array}$ & $\begin{array}{l}\text { High signal of } \\
\text { the anterior } \\
\text { chamber and } \\
\text { vitreous body }\end{array}$ & $\begin{array}{c}\text { Moderately } \\
\text { hyperintense }\end{array}$ & High signal \\
\hline $\begin{array}{l}\text { Optic nerve } \\
\text { degeneration }\end{array}$ & $\begin{array}{l}\text { Moderately } \\
\text { hyperintense }\end{array}$ & - & - & - \\
\hline $\begin{array}{c}\text { Iris neovascular- } \\
\text { ization }\end{array}$ & Low signal & $\begin{array}{l}\text { Intermediate } \\
\text { signal }\end{array}$ & $\begin{array}{l}\text { Conspicuous } \\
\text { enhancement } \\
\text { of the ciliary } \\
\text { body }\end{array}$ & - \\
\hline $\begin{array}{l}\text { Radiation- } \\
\text { induced } \\
\text { cataract }\end{array}$ & - & $\begin{array}{l}\text { Peripheral high } \\
\text { signal }\end{array}$ & $\begin{array}{c}\text { Peripheral } \\
\text { high signal }\end{array}$ & - \\
\hline $\begin{array}{c}\text { Periocular } \\
\text { fibrotic adhesion }\end{array}$ & Low signal & Low signal & - & - \\
\hline
\end{tabular}

\section{Discussion}

The aim of our study was to elucidate the MR semeiotics of radiotherapy-induced changes on both neoplastic tissues and healthy ocular structures in patients with uveal melanoma undergoing secondary enucleation after proton beam radiotherapy. When performing this MR imaging-pathologic correlation we took into account certain histopathologic features and compared them with individually matched MR images. 
The histopathologic appearance of eyes with uveal melanoma undergoing secondary enucleation after radiotherapy is different from that of eyes undergoing primary enucleation. Saornil et al. [27] and Avery et al. [19] described the histopathologic changes in eyes with uveal melanoma that had undergone secondary enucleation after proton beam radiotherapy and plaque brachytherapy, respectively, comparing them with those of primary enucleation. Irradiated lesions demonstrated more inflammation, necrosis, fibrosis, blood vessel damage, and hemorrhage, as well as fewer mitoses than nonirradiated tumors $[19,27]$. As for extratumoral findings, eyes undergoing secondary enucleation had more vitreous hemorrhage and iris neovascularization [19].

Previous authors have postulated a direct relationship between the duration of the time frame between radiotherapy and enucleation and the amount of histopathological alterations [24]. According to Seddon et al., in particular, areas of necrosis were more numerous and extensive several months after irradiation [24]. Necrosis in irradiated tumors is the result of a dual effect: (1) a direct cytotoxic effect of radiation on neoplastic cells, and (2) an indirect action through the damage of neoplastic vasculature with resultant ischemia. Immune response against degenerated and necrotic neoplastic cells, in the form of inflammatory infiltrates (often with a perivascular distribution), would also play a role in tumor regression [24,27]. From a histological point of view, radiation-induced necrosis is characterized by dispersion of the melanin pigment with storage of pigmentladen macrophages [32]. In our study, at the histopathologic examination, we found necrosis in 5/9 irradiated tumors; in 4 of these patients necrosis was seen under MR imaging. Radiation-induced necrosis had a peculiar appearance under MR imaging. It showed low signal intensity on T2-weighted images because of melanin pigment dispersion. Moreover, when proton beam radiotherapy-induced necrosis and viable neoplastic tissue were present in the treated tumor, the border between these two areas was well-defined under MRI. This finding, particularly evident in T2-weighted sequences, had a strong overlap with histopathology, showing a stark transition between the two distinct portions of the tumor. Such an appearance is related to the physical properties of protons and, in particular, to the possibility of obtaining a highly collimated beam with minimal lateral scatter [22,23]. Therefore, the appearance of radiation-induced necrosis is different from that of spontaneous necrosis, observable in nonirradiated melanomas, especially in those of considerable size. Our observation is in contrast with that of Ferry et al. who, in a previous article, assumed the impossibility of the pathologist being able to distinguish radiation-induced necrosis from spontaneous necrosis in uveal melanomas [22]. On the other hand, Saornil et al., taking into account different histologic findings, managed to distinguish irradiated from nonirradiated eyes in $85 \%$ of cases of their series [27].

Gragoudas et al. suggested that the time course of necrotic alterations after radiotherapy could be related to the baseline dimensions of the neoplasm; in particular, small lesions would exhibit necrotic alterations earlier than large tumors [29]. We agree with this hypothesis, not only as regards the necrosis, but also with regard to another degenerative alteration-namely, fibrosis. Indeed, in our series, the choroidal melanoma that showed fibrotic alterations was a relatively small lesion (basal diameters $4 \times 4 \mathrm{~mm}$, prominence $6 \mathrm{~mm}$ ), and the time course from radiotherapy to enucleation was rather short. In this patient, exhibiting complete tumor regression in the form of fibrotic remnants, the low signal intensity on T2-weighted images was related to fibroblasts, collagen deposition, and the abundant presence of melanophages. Our data are consistent with those of Kincaid et al. who, in two uveal melanomas enucleated after proton beam radiotherapy, found areas of fibrosis characterized by storage of collagen inside the stroma [25]. In our opinion, however, factors other than tumor size should also be taken into account, such as tumor response to radiotherapy, which may be heterogeneous and related to other determinants, including histologic type, cell kinetics, and host immune response [33].

Inflammatory complications are rather common after proton beam radiotherapy, being reported in $28 \%$ of patients during the first 5 years of treatment. Tumor size is considered the main risk factor [34]. Inflammatory complications encompass a wide spectrum of 
clinical manifestations (uveitis, endophthalmitis, conjunctivitis, etc.). Early detection and treatment of intraocular inflammation after radiotherapy is crucial since, if misdiagnosed, such a complication may result in secondary enucleation, even in the absence of tumor recurrence [34].

Uveitis may affect the anterior segment (iritis), the ciliary body (cyclitis), the posterior segment (choroiditis), or the whole uveal layer (panuveitis). In this last case, MRI may reveal a thickening of the anterior segment and the posterior aspect of the globe, associated with conspicuous enhancement on fat-suppressed T1-weighted images acquired after contrast agent administration [35].

In endophthalmitis the inflammatory process causes an increase in the protein content of the vitreous body and anterior chamber, due to leakage from retinal and choroidal vessels [35]. These vitreous changes are easily detectable in the form of increased signal intensity on unenhanced T1-weighted sequences, and also on T2-weighted FLAIR sequences commonly used in the brain MR protocol. On the other hand, vitreous alterations are less visible on contrast-enhanced T1-weighted sequences (because of modifications of the MR dynamic range induced by gadolinium) and hardly detectable on T2-weighted images . Uveitis and endophthalmitis can coexist, and may also be associated with choroidal and retinal detachment [35].

It has been hypothesized that in the pathogenesis of radiation-related inflammation, tumor necrosis plays a relevant role through the release of proinflammatory cytokines [34]. This assumption is consistent with our series; in the patient showing the most severe inflammatory complications, with concomitant panuveitis and endophthalmitis, the choroidal melanoma was wholly replaced by necrosis without appreciable neoplastic tissue. This patient underwent secondary enucleation four years after proton beam radiotherapy. In this case, at gross examination, the eyeball was surrounded by pus, and the posterior chamber showed necrotic-hemorrhagic content. Under MRI the edematous thickening of the periocular tissues displayed high signal intensity on fat-suppressed T2-weighted (STIR) images, restricted diffusion on DW images, and marked enhancement on contrastenhanced fat-suppressed T1-weighted images. Moreover, the last sequence excellently demonstrated the diffuse thickening and enhancement of the detached choroid. The alterations to the anterior chamber and vitreous body, typically seen in endophthalmitis, were better demonstrated on unenhanced T1-weighted sequences.

Chronic conjunctivitis is a rather common complication following proton beam radiotherapy, and is related both to the direct action of radiation on the conjunctival epithelium, and to changes in the tear film caused by the treatment [36]. In one enucleated eye of our series, at the histologic examination, we observed an evident (sub)-conjunctival inflammatory infiltrate consistent with chronic conjunctivitis. Following MR this alteration was clearly detectable only on fat-suppressed T1-weighted sequences acquired after contrast medium administration, which showed a conspicuous enhancement and thickening of the conjunctiva of the treated eye. On the other hand, these findings were hardly or not at all perceptible on T2-weighted and plain T1-weighted sequences.

Vitreous hemorrhage is observable in about $8 \%$ of patients treated with proton beam radiotherapy. It is less common after proton beam radiotherapy than after brachytherapy. In cases of recurrent vitreous hemorrhage, enucleation can be indicated because of the impossibility of performing a correct fundoscopic evaluation during follow-up [37]. The composition of the vitreous body (acellular fluid with 99\% water content) explains its physiological water-like appearance under MRI [38]. In our series, vitreous hemorrhage occurred in 2/9 patients; in identifying this alteration, T1-weighted sequences performed better than T2-weighted ones, due to T1 shortening provided by subacute blood products (methemoglobin). The anterior chamber and the vitreous body lost their physiological water-like appearance and became hyperintense on T1-weighted images. The appearance on T2-weighted images may vary depending on the severity and the age of bleeding, and sometimes a fluid-fluid level with a relatively low signal intensity of the dependent portion can be seen. The T2-weighted FLAIR sequence of the brain study may also be of 
help in detecting vitreous hemorrhage, easily demonstrating the loss of the physiological water-like hypointensity of the vitreous body.

Seddon et al. reported a series of three patients in which secondary enucleation was performed because of proton beam radiotherapy-related complications. In the patient with the longest time interval between irradiation and enucleation (11 months), the authors found optic nerve atrophy under light microscopy, although the tumor involved the ciliary body and choroid without covering the optic disc [24]. Kincaid et al. reported a series of five patients with uveal melanoma treated with proton beam radiotherapy, in which secondary enucleation was performed because of clinical complications and tumor growth. In two patients the authors described optic nerve atrophy; moreover, in these cases the tumor was away from the optic disc [25]. In our series, three patients showed optic nerve degeneration at the histologic examination and corresponding optic nerve thinning with T2 hyperintensity under MRI; in these cases, the tumor involved the optic disc. Whether optic nerve degeneration represents the result of the location of the lesion covering the optic nerve head, the consequence of the radiotherapy, or both, is debatable. The slightly hyperintense signal of the optic nerve we observed on T2-weighted images resembles the appearance of the subacute and chronic phases of Wallerian degeneration-a progressive anterograde disintegration of axons associated with demyelination following an injury to the cell body or the proximal portion of the axon [39]. In our case the optic nerve, formed by the axons of the ganglion cells of the retina, represents the first neuron of the visual pathway, extending from the ganglion cell layer of the retina to the lateral geniculate body of the thalamus. Ganglion cell injury - caused by tumor invasion, by radiation, or by both-determined, in turn, the degeneration of the axons constituting the optic nerve. These changes were displayed under MRI in the form of hyperintensity on T2-weighted images, volume loss (nerve thinning), and atrophy.

Neovascular glaucoma is one of the most serious complications of radiotherapy, as well as a leading indication for secondary enucleation [25]. Avery et al. found iris neovascularization in 39\% of the irradiated eyes undergoing secondary enucleation after plaque brachytherapy, and postulated that this alteration could be the result of radiationinduced ischemia [19]. In the case reported by Ferry et al. of a ciliary body melanoma enucleated after proton beam radiotherapy, the patient exhibited rubeosis iridis-iris neovascularization involving both the treated and the untreated areas [22]. Boyd et al. investigated the pathogenesis of iris neovascularization, and its link with irradiation, in 11 patients who underwent secondary enucleation after proton beam radiotherapy. Differently from the previous author, they found that neovascularization more often affected the nonirradiated side of the iris, and when it was observable on both sides of the iris, it was more conspicuous on the untreated side [21]. The pathogenesis of iris neovascularization and neovascular glaucoma has been clarified in the last few decades. It has been postulated that the detached retina, the tumor, and even the residual scar resulting from irradiation of the neoplasm, synthesize angiogenic factors that, in turn, would be responsible for iris neovascularization [21,37]. This theory is consistent with our own case series, in which the patient with neovascular glaucoma showed only a residual fibrotic remnant of the choroidal melanoma after radiotherapy. Neovascular glaucoma was characterized by a noticeable neovascularization of the iris and the ciliary body, and at the histological examination appeared as copious congested end ectatic vessels. Under MRI the angiogenic process manifested in the form of a considerable enhancement of the ciliary body (and the anterior portion of the choroid) on fat-suppressed T1-weighted images obtained after contrast agent administration.

Cataracts are another complication ascribable to radiotherapy, affecting about $33 \%$ of patients treated with proton beam radiotherapy. The physical properties of protons allow for the sparing of healthy tissues located both on the sides of and behind the lesion; however, the amount of radiation at the entrance of the beam can be comparatively high, thereby promoting the development of a cataract [37]. In their series Kincaid et al. described a dense cataract in one patient. In this case, at the histological examination, the lens 
cortex displayed vacuolation, fragmentation of fibers, and development of globules [25]. In our series one patient experienced a cataract; in this case, under MR imaging, the involved lens demonstrated a peripheral hyperintense rim on T1-weighted sequences. This particular appearance somehow resembles cortical laminar necrosis, a pathological phenomenon associated with hypoxia, status epilepticus, infections, metabolic diseases, and drug intoxication. Cortical laminar necrosis is characterized by a high signal intensity on T1-weighted sequences, with gyral distribution at the level of cortical brain lesions; gyriform T1 hyperintensity is related to the storage of necrotic debris and denatured proteins [40-42]. Similarly, it is conceivable that the hyperintense T1 signal we observed in the peripheral portion of the lens may be the result of radiation-induced damage to the proteins of the cortical fibers and the accumulation of debris in the subcapsular region of the lens [28].

In previous articles, some authors reported a noticeable impediment during enucleation because of the dense fibrotic adhesions resulting from radiotherapy [22,43]. In our series, we observed similar findings in one patient who underwent secondary enucleation three years after proton beam radiotherapy because of local recurrence of a choroidal melanoma. The histologic examination showed the thickening of the sclera in close proximity to the insertion of the superior rectus muscle, in correspondence to the tantalum clips used to delimit the tumor borders before proton beam treatment. Under MR imaging the soft tissue thickening along the outer edge of the sclera was better visible on T2-weighted images, in which fibrotic alteration appeared hypointense because of collagen fiber deposition.

To our knowledge, to date, ours is the first study making a radiologic-pathologic correlation of MR findings and histopathologic data of uveal melanomas treated with proton beam radiotherapy undergoing secondary enucleation. To elucidate the MR appearance of alterations induced by radiotherapy on neoplastic and healthy ocular tissues has twofold relevance, since it helps us to understand the pathological basis of the effects of radiation, and also enhances the radiologist's diagnostic confidence in the evaluation of follow-up MR examinations of patients with uveal melanoma. Indeed, during the last few years radiologists have acquired an increasingly important role in the multidisciplinary approach to patients with uveal melanoma. Although the detection of radiotherapy-related complications is not the primary aim of MR imaging, the thorough assessment of the effects of radiotherapy on both neoplastic and ocular tissue, and the confirmation of the clinical findings of the MR examination, may be crucial in patients' multidisciplinary management and, in particular, in choosing whether or not to perform enucleation.

Admittedly, our study has various limitations. The small sample size and retrospective design were the main limitations of our study. Nevertheless, it should be noted that uveal melanoma is a rare neoplasm and, fortunately, enucleation has become increasingly uncommon in the last decade. MR examinations were performed at only one time point, just before enucleation; no MRI was performed at the time of diagnosis, before radiotherapy. The potential different orientation between MR images and histopathology slides could have made the radiologic-pathologic correlation in certain cases difficult; nevertheless, the use of specific anatomic landmarks (optic disc, ciliary body) has made it possible to overcome this obstacle. We deliberately did not take into account some extratumoral ocular findings, such as retinal detachment and choroidal detachment, because these findings can be related to the presence of the tumor and, therefore, already be present before radiotherapy. Lastly, we exclusively evaluated histopathological alterations with a counterpart in MR imaging; therefore, we did not take into account some purely histologic alterations observable in irradiated tumors, such as mitotic figures and balloon cells.

\section{Conclusions}

The radiologic-pathologic correlation between MR images and histopathological data after secondary enucleation enabled us to elucidate the MR semeiotics of radiotherapyinduced changes on neoplastic tissues and healthy ocular structures. Because of their 
relevant role in the multidisciplinary approach to uveal melanoma, and the responsibility that results from this, radiologists should be aware of the effects of radiotherapy on tissues and of their appearance at MR imaging. Enhancing accuracy in evaluating radiationinduced changes can help the multidisciplinary team make crucial clinical decisions and, ultimately, improve the therapeutic management of patients with uveal melanoma.

Moreover, although the MR protocol in the study of uveal melanoma is somewhat standardized, radiologists need to know the role and the diagnostic contribution of each MR pulse sequence in performing different specific tasks, in order to fully exploit the multiparametric capabilities of MRI. Overall, T2-weighted sequences perform better in detecting radiation-induced necrosis and fibrosis, as well as optic nerve degeneration and periocular fibrotic adhesions, whereas T1-weighted sequences are preferable for identifying alterations to the lens, vitreous hemorrhage, and inflammatory complications. Contrast-enhanced fat-suppressed T1-weighted sequences are irreplaceable in assessing iris neovascularization and confirming the presence of inflammatory complications.

Author Contributions: All authors listed have made a substantial, direct, and intellectual contribution to the work, and approved it for publication. All authors have read and agreed to the published version of the manuscript.

Funding: This research was funded by the research plan of the University of Catania: "PIAno di inCEntivi per la RIcerca di Ateneo 2020/2022"—Linea di intervento 3: STARTING GRANT 2020.

Institutional Review Board Statement: The study was carried out in accordance with The Code of Ethics of the World Medical Association (Declaration of Helsinki) for experiments involving humans, and in accordance with the recommendations of our local ethics committee.

Informed Consent Statement: Patient consent was waived because of the retrospective design of the study.

Data Availability Statement: The data presented in this study are available on request from the corresponding author.

Acknowledgments: The authors would like to thank the Department of Medical, Surgical, and Advanced Technologies "GF Ingrassia" of the University of Catania and the research plan of the University of Catania: "PIAno di inCEntivi per la RIcerca di Ateneo 2020/2022" — Linea di intervento 3: STARTING GRANT 2020.

Conflicts of Interest: The authors declare no conflict of interest.

\section{References}

1. Yonekawa, Y.; Kim, I.K. Epidemiology and Management of Uveal Melanoma. Hematol. Clin. N. Am. 2012, 26, 1169-1184. [CrossRef] [PubMed]

2. Kaliki, S.; Shields, C.L. Uveal melanoma: Relatively rare but deadly cancer. Eye 2017, 31, 241-257. [CrossRef] [PubMed]

3. Kivela, T.; Simpson, E.R.; Grossniklaus, H.E.; Jager, M.J.; Singh, A.D.; Caminal, J.M.; Pavlick, A.C.; Kujala, E.; Coupland, S.E.; Finger, P. Uveal melanoma. In AJCC Cancer Staging Manual; Springer: New York, NY, USA, 2017; pp. 805-817.

4. Russo, A.; Avitabile, T.; Reibaldi, M.; Bonfiglio, V.; Pignatelli, F.; Fallico, M.; Caltabiano, R.; Broggi, G.; Russo, D.; Varricchio, S.; et al. Iris Melanoma: Management and Prognosis. Appl. Sci. 2020, 10, 8766. [CrossRef]

5. Broggi, G.; Russo, A.; Reibaldi, M.; Russo, D.; Varricchio, S.; Bonfiglio, V.; Spatola, C.; Barbagallo, C.; Foti, P.V.; Avitabile, T.; et al. Histopathology and Genetic Biomarkers of Choroidal Melanoma. Appl. Sci. 2020, 10, 8081. [CrossRef]

6. Broggi, G.; Ieni, A.; Russo, D.; Varricchio, S.; Puzzo, L.; Russo, A.; Reibaldi, M.; Longo, A.; Tuccari, G.; Staibano, S.; et al. The Macro-Autophagy-Related Protein Beclin-1 Immunohistochemical Expression Correlates with Tumor Cell Type and Clinical Behavior of Uveal Melanoma. Front. Oncol. 2020, 10. [CrossRef]

7. Russo, D.; Di Crescenzo, R.M.; Broggi, G.; Merolla, F.; Martino, F.; Varricchio, S.; Ilardi, G.; Borzillo, A.; Carandente, R.; Pignatiello, S.; et al. Expression of P16INK4a in Uveal Melanoma: New Perspectives. Front. Oncol. 2020, 10, 562074. [CrossRef]

8. Foti, P.V.; Farina, R.; Coronella, M.; Palmucci, S.; Montana, A.; Sigona, A.; Reibaldi, M.; Longo, A.; Russo, A.; Avitabile, T.; et al. Diffusion-weighted magnetic resonance imaging for predicting and detecting the response of ocular melanoma to proton beam therapy: Initial results. Radiol. Med. 2015, 120, 526-535. [CrossRef]

9. Russo, A.; Mariotti, C.; Longo, A.; Foti, P.V.; Avitabile, T.; Uva, M.G.; Franco, L.M.; Bonfiglio, V.; Milone, P.; Ettorre, G.C.; et al. Diffusion-weighted magnetic resonance imaging and ultrasound evaluation of choroidal melanomas after proton-beam therapy. Radiol. Medica 2015, 120, 634-640. [CrossRef] 
10. Foti, P.V.; Longo, A.; Reibaldi, M.; Russo, A.; Privitera, G.; Spatola, C.; Raffaele, L.; Salamone, V.; Farina, R.; Palmucci, S.; et al. Uveal melanoma: Quantitative evaluation of diffusion-weighted MR imaging in the response assessment after proton-beam therapy, long-term follow-up. Radiol. Med. 2017, 122, 131-139. [CrossRef]

11. Ferreira, T.A.; Fonk, L.G.; Jaarsma-Coes, M.G.; Van Haren, G.G.R.; Marinkovic, M.; Beenakker, J.-W.M. MRI of Uveal Melanoma. Cancers 2019, 11, 377. [CrossRef]

12. Zimmerman, L.E.; McLean, I.W.; Foster, W.D. Does enucleation of the eye containing a malignant melanoma prevent or accelerate the dissemination of tumour cells. Br. J. Ophthalmol. 1978, 62, 420-425. [CrossRef]

13. Tarlan, B.; Kıratlı, H. Uveal Melanoma: Current Trends in Diagnosis and Management. Turk. J. Ophthalmol. 2016, 46, 123-137. [CrossRef]

14. Puusaari, I.; Heikkonen, J.; Summanen, P.; Tarkkanen, A.; Kivelä, T. Iodine brachytherapy as an alternative to enucleation for large uveal melanomas. Ophthalmology 2003, 110, 2223-2234. [CrossRef]

15. Diener-West, M.; Earle, J.D.; Fine, S.L.; Hawkins, B.S.; Moy, C.S.; Reynolds, S.M.; Schachat, A.P.; Straatsma, B.R.; Collaborative Ocular Melanoma Study Group. The COMS Randomized Trial of Iodine 125 Brachytherapy for Choroidal Melanoma, III: Initial Mortality Findings. Arch. Ophthalmol. 2001, 119, 969-982. [CrossRef]

16. Collaborative Ocular Melanoma Study Group. The COMS Randomized Trial of Iodine 125 Brachytherapy for Choroidal Melanoma: V. Twelve-year mortality rates and prognostic factors: COMS report No. 28. Arch. Ophthalmol. 2006, 124, 1684-1693. [CrossRef]

17. Jampol, L.M.; Moy, C.S.; Murray, T.G.; Reynolds, S.M.; Albert, D.M.; Schachat, A.P.; Diddie, K.R.; Engstrom, R.; Finger, P.T.; Hovland, K.R.; et al. The COMS randomized trial of iodine 125 brachytherapy for choroidal melanoma. Ophthalmology 2002, 109, 2197-2206. [CrossRef]

18. Aziz, S. Proton beam radiotherapy in the management of uveal melanoma: Clinical experience in Scotland. Clin. Ophthalmol. 2008, 3, 49. [CrossRef]

19. Avery, R.B.; Diener-West, M.; Reynolds, S.M.; Grossniklaus, H.E.; Green, W.R.; Albert, D.M. Histopathologic Characteristics of Choroidal Melanoma in Eyes Enucleated After Iodine 125 Brachytherapy in the Collaborative Ocular Melanoma Study. Arch. Ophthalmol. 2008, 126, 207-212. [CrossRef]

20. Hager, A.; Meissner, F.; Riechardt, A.; Bonaventura, T.; Löwen, J.; Heufelder, J.; Joussen, A.M. Breakdown of the blood-eye barrier in choroidal melanoma after proton beam radiotherapy. Graefe's Arch. Clin. Exp. Ophthalmol. 2019, 257, 2323-2328. [CrossRef]

21. Boyd, S.R.; Gittos, A.; Richter, M.; Hungerford, J.L.; Errington, R.D.; Cree, I. Proton beam therapy and iris neovascularisation in uveal melanoma. Eye 2005, 20, 832-836. [CrossRef]

22. Ferry, A.P.; Blair, C.J.; Gragoudas, E.S.; Volk, S.C. Pathologic Examination of Ciliary Body Melanoma Treated with Proton Beam Irradiation. Arch. Ophthalmol. 1985, 103, 1849-1853. [CrossRef] [PubMed]

23. Zinn, K.M.; Stein/pokorny, K.; Jakobiec, F.A.; Friedman, A.H.; Gragoudas, E.S.; Ritch, R. Proton-Beam Irradiated Epithelioid Cell Melanoma of the Ciliary Body. Ophthalmology 1981, 88, 1315-1321. [CrossRef]

24. Seddon, J.M.; Gragoudas, E.S.; Albert, D.M. Ciliary Body and Choroidal Melanomas Treated by Proton Beam Irradiation. Arch. Ophthalmol. 1983, 101, 1402-1408. [CrossRef]

25. Kincaid, M.C.; Folberg, R.; Torczynski, E.; Zakov, Z.N.; Shore, J.W.; Liu, S.J.; Planchard, T.A.; Weingeist, T.A. Complications after Proton Beam Therapy for Uveal Mall nant Melanoma. Ophthalmology 1988, 95, 982-991. [CrossRef]

26. Lemke, A.-J.; Hosten, N.; Bornfeld, N.; Bechrakis, N.E.; Schuler, A.; Richter, M.; Stroszczynski, C.; Felix, R. Uveal Melanoma: Correlation of Histopathologic and Radiologic Findings by Using Thin-Section MR Imaging with a Surface Coil. Radiology 1999, 210, 775-783. [CrossRef] [PubMed]

27. Saornil, M.A.; Egan, K.M.; Gragoudas, E.S.; Seddon, J.M.; Walsh, S.M.; Albert, D.M. Histopathology of Proton Beam-Irradiated vs. Enucleated Uveal Melanomas. Arch. Ophthalmol. 1992, 110, 1112-1118. [CrossRef] [PubMed]

28. Groenewald, C.; Konstantinidis, L.; Damato, B. Effects of radiotherapy on uveal melanomas and adjacent tissues. Eye 2013, 27, 163-171. [CrossRef]

29. Gragoudas, E.S.; Egan, K.M.; Saornil, M.A.; Walsh, S.M.; Albert, D.M.; Seddon, J.M. The Time Course of Irradiation Changes in Proton Beam-treated Uveal Melanomas. Ophthalmology 1993, 100, 1555-1560. [CrossRef]

30. Spatola, C.; Liardo, R.L.E.; Milazzotto, R.; Raffaele, L.; Salamone, V.; Basile, A.; Foti, P.V.; Palmucci, S.; Cirrone, G.A.P.; Cuttone, G.; et al. Radiotherapy of Conjunctival Melanoma: Role and Challenges of Brachytherapy, Photon-Beam and Protontherapy. Appl. Sci. 2020, 10, 9071. [CrossRef]

31. Goitein, M.; Miller, T. Planning proton therapy of the eye. Med. Phys. 1983, 10, 275-283. [CrossRef]

32. Font, R.L.; Croxatto, J.O.; Rao, N.A. Tumors of the Eye and Ocular Adnexa (Afip Atlas of Tumor Pathology, Series 4), 1st ed.; Amer Registry of Pathology: Washington, DC, USA, 2006; ISBN 1-881041-99-9.

33. Suit, H.; Skates, S.; Taghian, A.; Okunieff, P.; Efird, J.T. Clinical implications of heterogeneity of tumor response to radiation therapy. Radiother. Oncol. 1992, 25, 251-260. [CrossRef]

34. Lumbroso, L.; Desjardins, L.; Levy, C.; Plancher, C.; Frau, E.; D’Hermies, F.; Schlienger, P.; Mammar, H.; Delacroix, S.; Nauraye, C.; et al. Intraocular inflammation after proton beam irradiation for uveal melanoma. Br. J. Ophthalmol. 2001, 85, 1305-1308. [CrossRef]

35. Mafee, M.F.; Karimi, A.; Shah, J.; Rapoport, M.; Ansari, S.A. Anatomy and Pathology of the Eye: Role of MR Imaging and CT. Neuroimaging Clin. N. Am. 2005, 15, 23-47. [CrossRef] 
36. Choi, Y.J.; Kim, T.W.; Kim, S.; Choung, H.; Lee, M.J.; Kim, N.; Khwarg, S.I.; Yu, Y.S. Effects on Periocular Tissues after Proton Beam Radiation Therapy for Intraocular Tumors. J. Korean Med. Sci. 2018, 33, 120. [CrossRef]

37. Desjardins, L.; Rouic, L.L.-L.; Levy-Gabriel, C.; Cassoux, N.; Dendale, R.; Mazal, A.; Delacroix, S.; Sastre, X.; Plancher, C.; Asselain, B. Treatment of Uveal Melanoma by Accelerated Proton Beam. Dev. Ophthalmol. 2011, 49, 41-57. [CrossRef]

38. Polo, M.D.L.H.; Lluís, A.T.; Segura, O.P.; Bosque, A.A.; Appiani, C.E.; Mitjana, J.M.C. Ocular ultrasonography focused on the posterior eye segment: What radiologists should know. Insights Imaging 2016, 7, 351-364. [CrossRef]

39. Chen, Y.J.; Nabavizadeh, S.A.; Vossough, A.; Kumar, S.; Loevner, L.A.; Mohan, S. Wallerian Degeneration Beyond the Corticospinal Tracts: Conventional and Advanced MRI Findings. J. Neuroimaging 2017, 27, 272-280. [CrossRef]

40. Niwa, T.; Aida, N.; Shishikura, A.; Fujita, K.; Inoue, T. Susceptibility-Weighted Imaging Findings of Cortical Laminar Necrosis in Pediatric Patients. Am. J. Neuroradiol. 2008, 29, 1795-1798. [CrossRef]

41. Donaire, A.; Carreno, M.; Gómez, B.; Fossas, P.; Bargalló, N.; Agudo, R.; Falip, M.; Setoaín, X.; Boget, T.; Raspall, T.; et al. Cortical laminar necrosis related to prolonged focal status epilepticus. J. Neurol. Neurosurg. Psychiatry 2006, 77, 104-106. [CrossRef]

42. Boyko, O.B.; Burger, P.C.; Shelburne, J.D.; Ingram, P. Non-heme mechanisms for T1 shortening: Pathologic, CT, and MR elucidation. Am. J. Neuroradiol. 1992, 13, 1439-1445.

43. Pham, C.M.; Custer, P.L.; Couch, S.M. Comparison of primary and secondary enucleation for uveal melanoma. Orbit 2017, 36, 422-427. [CrossRef] 